\title{
Erratum to: Characteristics of single-case designs used to assess intervention effects in 2008
}

\author{
William R. Shadish • Kristynn J. Sullivan
}

Published online: 8 November 2014

(C) Psychonomic Society, Inc. 2014

Erratum to: Behav Res

10.3758/s13428-011-0111-y

Published Vol 43 No 4, pp. 971-980

The second equation on page 978 erroneously contained a minus sign at the start of the right side of the equation. The correct equation is

$\rho=\frac{r t+4}{t-3}$

The error did not affect any reported results because all statistical analyses used the correct equation.

The online version of the original article can be found at: http://dx.doi.org/ 10.3758/s13428-011-0111-y.

W. R. Shadish $\cdot$ K. J. Sullivan

University of California, Merced, CA, USA

W. R. Shadish $(\bowtie)$

School of Social Sciences, Humanities and Arts, University of California, Merced, 5200 North Lake Rd, Merced, CA 95343, USA

e-mail: wshadish@ucmerced.edu 